\title{
A rare case of massive papillary fibroelastoma of the right ventricular free wall
}

\author{
T. Baks • T. W. Galema • J. Bakker • M. J. M. Kofflard
}

Published online: 24 May 2011

(C) The Author(s) 2011. This article is published with open access at Springerlink.com

\begin{abstract}
A 51-year-old previously healthy woman was referred to our institution with atypical chest pain. Physical examination and laboratory findings were normal. The electrocardiogram demonstrated sinus rhythm of 70 beats/min with a right bundle branch block. Routine chest X-ray showed calcifications projecting on the heart. Transthoracic echocardiography was hampered by a limited acoustic window. Cardiovascular magnetic resonance revealed a well-demarcated mass in the right ventricle in conjunction with the right ventricular free wall (Fig. 1). Dimensions were $9.5 \times 4.5 \times 4.5 \mathrm{~cm}$. Computed tomography of the thorax demonstrated a densely calcified mass located in the right ventricle but showed no evidence of pulmonary embolism or intrapulmonary masses (Fig. 2a and b). Finally, transvenous biopsy of the tumour led to the histological diagnosis of papillary fibroelastoma (Fig. 2d). To our knowledge, this is the first well-documented case of a large calcified papillary fibroelastoma of the right ventricular free wall $[1,2]$.
\end{abstract}

T. Baks $\cdot$ M. J. M. Kofflard

Department of Cardiology, Albert Schweitzer Hospital,

Dordrecht, the Netherlands

T. Baks $\cdot$ T. W. Galema

Department of Cardiology, Erasmus MC,

Rotterdam, the Netherlands

J. Bakker

Department of Radiology, Albert Schweitzer Hospital,

Dordrecht, the Netherlands

T. Baks $(\bowtie)$

Albert Schweitzer Hospital,

Albert Schweitzerplaats 25,

3318 AT, Dordrecht, the Netherlands

e-mail: t.baks@erasmusmc.nl
Acknowledgments We would like to thank Angela J. Stavast-Kooy, $\mathrm{MD}$, from the department of pathology of the Erasmus MC, Rotterdam, the Netherlands for her assistance in analysing the histological data.

Open Access This article is distributed under the terms of the Creative Commons Attribution Noncommercial License which permits any noncommercial use, distribution, and reproduction in any medium, provided the original author(s) and source are credited.

\section{References}

1. Gowda RM, Khan IA, Nair CK, et al. Cardiac papillary fibroelastoma: a comprehensive analysis of 725 cases. Am Heart J. 2003;146:404-10.

2. Sun JP, Asher CR, Yang XS, et al. Clinical and echocardiographic characteristics of papillary fibroelastomas: a retrospective and prospective study in 162 patients. Circulation. 2001;103:2687-93. 
Fig. 1 Cardiovascular magnetic resonance (CMR) demonstrates a large mass in the right ventricle in conjunction with the right ventricular free wall. On cine-imaging, the mass exhibited a somewhat lower signal than the left ventricular myocardium (a and b). T1 (c) and T2 (d) weighted imaging demonstrate a heterogeneous signal from the tumour ranging from isointense to almost non-existing signal

Fig 2 Axial (a) and (b) coronal CT image show a large and heavily calcified mass at the right ventricular free wall. Coronary angiography (c) shows a large non vascularised calcified mass. Histological examination (d) in haematoxylin and eosin stain reveals a papillary frond with a superficial endothelial layer, and an intermediate layer of connective tissue with a central avascular core
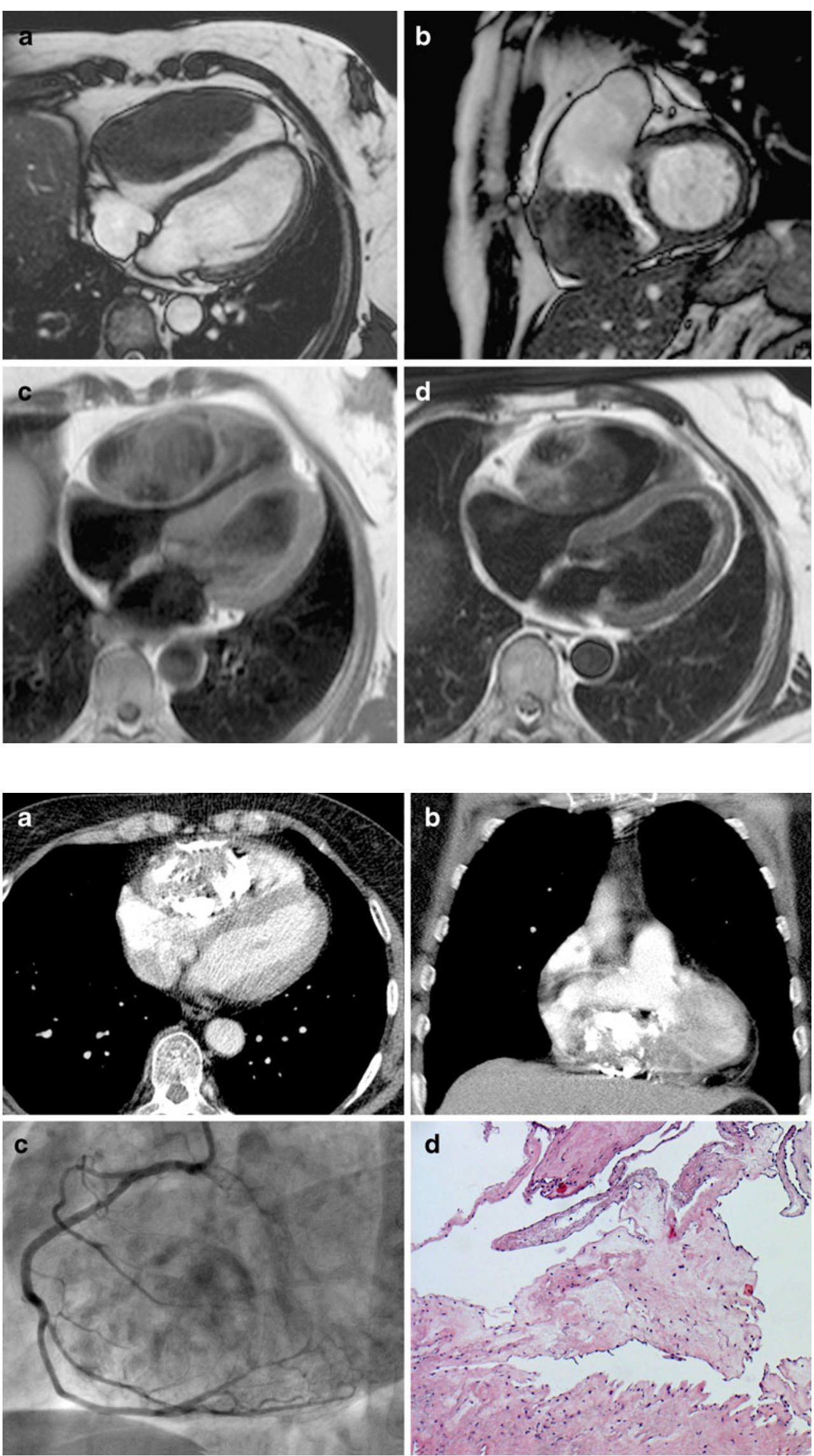